\title{
Câncer melanoma e não melanoma: potenciais benefícios da fitoterapia no tratamento de lesões dermatológicas oncológicas
}

\section{Melanoma and non-melanoma cancer: potential benefits of herbal medicine in the treatment of oncological dermatological lesions}

Recebimento dos originais: 01/05/2021

Aceitação para publicação: 31/06/2021

\section{Aline Aparecida da Silva Cunha}

Instituição: Universidade de Uberaba (UNIUBE), Uberaba - Minas Gerais.

\section{Aline Arantes Lima}

Instituição: Universidade de Uberaba (UNIUBE), Uberaba - Minas Gerais.

Sofia Barcelo Oliveira

Instituição: Universidade de Uberaba (UNIUBE), Uberaba - Minas Gerais.

\author{
Aldo Matos \\ Instituição: Universidade de Uberaba (UNIUBE), Uberaba - Minas Gerais.
}

\section{RESUMO}

O estudo buscou evidenciar, por meio de revisão de literatura, os benefícios da fitoterapia em lesões dermatológicas oncológicas. Constatou-se que o uso de plantas medicinais contribui significativamente para cicatrização e controle de dor em sítio tumoral e adjacências.

Palavras-chave: Fitoterapia, Ferimentos e Lesões, Neoplasias Cutâneas.

\begin{abstract}
This study aimed to show, through a literature review, the benefits of phytotherapy in oncologic dermatologic lesions. It was found that the use of medicinal plants contributes significantly to healing and pain control in tumor sites and adjacencies.
\end{abstract}

Keywords: Phytotherapy, Wounds and Injuries, Cutaneous Neoplasms.

\section{INTRODUÇÃO}

O câncer é definido pelo crescimento desordenado e incontrolável das células, podendo acometer diversos órgãos ou tecidos. As neoplasias que acometem a pele correspondem a cerca de $30 \%$ de todos os tumores malignos registrados no Brasil, sendo divididas em melanomas - maior frequência e alto percentual de cura - e não melanomas - menor incidência e maior agressividade metastática (INCA, 2019).

Terapêuticas disponíveis para neoplasias dermatológicas envolvem exérese cirúrgica da lesão, radioterapia e quimioterapia (INCA, 2019). Paralelamente a este contexto, estudos evidenciam que 30 a 
$50 \%$ dos pacientes oncológicos em tratamento fazem uso de terapias complementares associadas (LOPES et al, 2017). Em 2006, o Ministério da Saúde do Brasil, lançou a Política Nacional de Práticas Integrativas e Complementares (PNPIC) que regulamenta a prescrição das mesmas pelo Sistema Único de Saúde (SUS). Dentre as práticas integrativas, destaca-se a fitoterapia, terapêutica que utiliza das plantas medicinais incorporadas nas diversas formas terapêuticas, não utilizando somente a substância ativa, mas sim os extratos em si (BRASIL, Política Nacional de Práticas Integrativas e Complementares no SUS, 2018).

\section{OBJETIVO}

Evidenciar potenciais benefícios do uso complementar de fitoterápicos no tratamento de lesões dermatológicas causadas por canceres melanoma e não melanoma; efeitos cicatrizantes, controle de dor e odor promovidos por plantas medicinais em terapêutica tópica de feridas oncológicas em pele com menor probabilidade de efeitos colaterais.

\section{MÉTODO}

Realizou-se uma revisão de literatura, compreendendo busca de artigos científicos nas bases de dados SciELO, Biblioteca Virtual em Saúde, PubMed, Google Acadêmico e pesquisa de informações nos sites institucionais Journal of Cancer e Instituto Nacional do Câncer. Os artigos foram selecionados com base nas seguintes palavras-chaves: "feridas tumorais", "lesões oncológicas", "fitoterapia", “fitoterapia e úlceras dermatológicas”, "plantas medicinais e cicatrização de feridas”, "melanoma”, "não melanoma". Foram incluídos artigos originais em língua portuguesa e inglesa, publicados nos últimos 5 anos, de 2016 a 2021, a respeito do uso de fitoterapia no tratamento complementar de feridas dermatológicas oncológicas. Há poucos dados na literatura sobre o uso de fitoterápicos no tratamento tópico das lesões de pele oncológicas, necessitando de mais estudos acerca deste tema.

\section{RESULTADOS}

A amostra final da revisão literária foi constituída por 6 artigos selecionados por critérios de inclusões previamente definidos, destes, 2 foram encontrados na base de dados Scielo, 1 na PubMed, 1 na Biblioteca Virtual de Saúde, 2 no Google Acadêmico (Quadro 1) e informações cientificamente fundamentas coletadas no site do Instituto Nacional do Câncer e Journal of Câncer.

A fundamentação teórica é composta por artigos que abordam efeitos e potenciais usos de fitoterápicos em lesões dermatológicas causadas por tumores malignos; literatura relacionada as Práticas Integrativas e Complementares e os benefícios do tratamento complementar com uso tópico de plantas medicinais; escritos científicos que abordam definição e fisiopatologia de canceres melanoma e não 
melanoma na origem de lesões oncológicas dermatológicas e sintomas associados, somados as intervenções terapêuticas disponíveis atualmente.

Em relação aos resultados, demonstrou-se os benefícios de cicatrização eficaz, desbridamento de tecido necrótico, controle de dor no sítio da ferida e tecidos adjacentes, somado ao baixo custo da terapêutica complementar em feridas dermatológicas desencadeadas por canceres melanoma e não melanoma.

Quadro 1 - Resultados da pesquisa bibliográfica por descritores e dos artigos selecionados para estudos

\begin{tabular}{|l|c|c|c|c|c|c|c|c|}
\hline DESCRITORES & \multicolumn{2}{|c|}{$\begin{array}{c}\text { BIBLIOTECA } \\
\text { VIRTUAL DE } \\
\text { SAÚDE }\end{array}$} & \multicolumn{2}{c|}{$\begin{array}{c}\text { GOOGLE } \\
\text { ACADÊMICO }\end{array}$} & \multicolumn{2}{c|}{ PUBMED } & \multicolumn{2}{c|}{ SCIELO } \\
\hline & Total & Seleção & Total & Seleção & Total & Seleção & Total & Seleção \\
\hline Fitoterapia & 2 & 1 & 2 & 1 & 1 & 0 & 2 & 1 \\
\hline $\begin{array}{l}\text { Ferimentos } \\
\text { lesões }\end{array}$ & 2 & 0 & 2 & 1 & 0 & 0 & 2 & 1 \\
\hline $\begin{array}{l}\text { Neoplasias } \\
\text { cutâneas }\end{array}$ & 1 & 0 & 1 & 0 & 2 & 1 & 1 & 0 \\
\hline
\end{tabular}

\section{DISCUSSÃO}

$\mathrm{O}$ avanço proliferativo celular associado a neovascularização de canceres melanoma e não melanoma promovem rápida formação e expansão de feridas neoplásicas com destruição necrótica tecidual local e adjacente ao sítio tumoral, levando a formação de exsudato purulento, odor fétido e dor (JUNIOR et al, 2019). A adjuvância com terapia tópica a base de plantas medicinais tem sido amplamente aplicada no tratamento de feridas dermatológicas (PINTO et al, 2020).Destaca-se o Aloe vera potente cicatrizante e redutor de dor; Calêndula officinalis com significativo potencial desbridante, diminui colonização bacterina associado a um alto poder de cicatrização, necessitando menor troca de curativos; Extrato de Symphytum officinale em creme com resposta de cicatrização de $85 \%$ (TOZZINI et al, 2019). Evidencia-se que o uso externo de fitoterápicos no tratamento de feridas de pele oncológicas promove cicatrização eficaz associada a mínima probabilidade de efeitos colaterais, uma vez que são aplicados produtos naturais, com baixo custo (ISABEL, 2019).

\section{CONSIDERAÇÕES FINAIS}

O uso tópico de plantas medicinais contribui significativamente para resposta eficaz na cicatrização e controle de dor e odor que constituem sintomas associados a feridas de pele e tecidos adjacentes desencadeadas por canceres melanoma e não melanomas. A fitoterapia é uma Prática Integrativa e Complementar de baixo custo, raros efeitos colaterais e que apresenta significativos benefícios que evidenciam seu grande potencial para uso complementar no tratamento adjuvante de lesões oncológicas dermatológicas, contribuindo para melhor qualidade e resposta terapêutica. 


\section{REFERÊNCIAS}

1. INCA. O que é câncer. Disponível em: https://www.inca.gov.br/o-que-e-cancer. Acesso em: 01 de maio de 2021.

2. INCA. Câncer de pele melanoma. Disponível em: https://www.inca.gov.br/tipos-decancer/cancer-de-pele-melanoma/profissional-de-saude. Acesso em: 01 de maio de 2021.

3. INCA. Câncer de pele não melanoma. Disponível em: https://www.inca.gov.br/tipos-decancer/cancer-de-pele-nao-melanoma/profissional-de-saude. Acesso em: 01 de maio de 2021.

4. JUNIOR, J. F.; POLAKIEWICZ, R. R.; FULY, P. DOS S. C. Feridas tumorais e suas implicações para o cuidado de enfermagem. Revista Enfermagem Atual In Derme, v. 85, n. 23, 1 abr. 2019.

5. LOPEZ G, et al. Integrative oncology physician consultations at a comprehensive cancer center: Analysis of demographic, clinical and patient reported outcomes. J Cancer. 2017;8(3):395-402.

6. PINTO, E. G.; CAVALCANTE, F.S.; LIMA, R. A. A fitoterapia no tratamento de pele: um estudo bibliográfico. Revista Biodiversidade, v. 19 n.3, 2020.

7. Política nacional de práticas integrativas e complementares no SUS: atitude de ampliação de acesso / Ministério da Saúde. Secretaria de Atenção à Saúde. Departamento de Atenção Básica. - 2. ed., 1. reimpr. - Brasília: Ministério da Saúde, 2018.

8. SCHALCH, Isabel. A fitoterapia como opção terapêutica complementar em pacientes oncológicos. 2019. Trabalho de conclusão de curso (Bacharelado em Farmácia) - Universidade

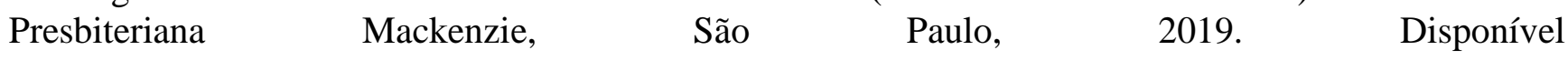
em: http://dspace.mackenzie.br/handle/10899/20876.

9. Tozzini JL, Mamede RF, Francisco D, Jorgetto JV, Jorgetto GV. Uso de fitoterápicos em cicatrização de lesão por pressão - scoping review. J Assis Farm Farmacoec. 2019; 4(1): 14-20. 